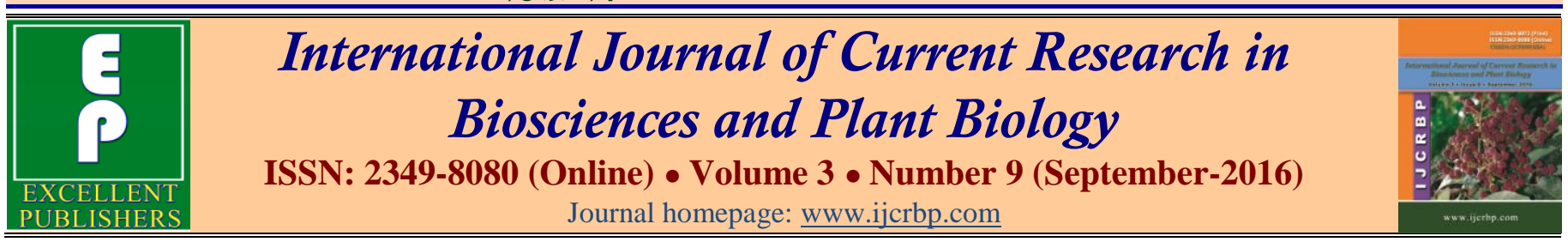

Review Article

doi: http://dx.doi.org/10.20546/ijcrbp.2016.309.011

\title{
A Review on Prospects of Entomopathogenic Fungi as Potent Biological Control Agents of Insect Pests
}

\author{
Elangbam Bidyarani Devi ${ }^{1}$, Elangbam Premabati Devi ${ }^{*}$ and Deepshikha $^{2}$
}

${ }^{1}$ Department of Entomology, Assam Agricultural University, Jorhat-785 013, Assam, India

2Department of Plant Pathology, G.B.P.U.A.T., Pantnagar-263 145, Uttarakhand, India

*Corresponding author.

\begin{abstract}
A b st ract
Insecticide resistance and the demand for reduced chemical inputs in agriculture have provided a movement to the development of alternative measures of controlling insect pests. Myco-biocontrol offers an attractive alternative to the use of chemical pesticides. Entomopathogenic fungi are potential biological control agents mainly by reason of their wide host range, high reproductive capabilities, target specific activity, short generation time, and resting stage or saprobic phase producing capabilities that can ensure their survival for a longer time when no host is present. However, a primary requirement for the commercial use of entomopathogenic fungus as myco-biocontrol agents is the susceptibility of the insect and also the virulence of the fungus. They are naturally occurring organisms which are perceived as less damaging to the environment. The current paper could enlightened regarding the recent progress in the field of entomopathogenic fungi and their possible mode of action along with further improvement aspects for perceptive of myco-biological control of insect pests.
\end{abstract}

\section{Article Info}

Accepted: 27 August 2016

Available Online: 06 September 2016

\section{Ke ywords}

Biopesticide

Entomopathogenic fungi

Myco-biocontrol

Resistance

\section{Introduction}

The various risk associated with the continuous use of chemical insecticides mainly development of resistance, resurgence in insects, accumulation of pesticidal residues in food chain, environmental pollution, health risks have led to development of alternative strategies of pest management. The necessity for sustainable crop production through eco-friendly pest management technique is being largely felt in recent times. Thus, the exploitation of biocontrol agents is considered as a suitable alternative to the use of chemical pesticides (Dhaliwal and Koul, 2007). Among the various biocontrol agents, entomopathogenic fungi are being a major component of an integrated approach that can provide significant and selective insect control. Because of their wide host range they are potentially the most versatile biological control agents. These fungi comprise a diverse group of over 100 genera with approximately 750 species, reported from different insects. They vary considerably in their mode of action and virulence. Myco-biocontrol is an environmentally sound and effective means of reducing insect-pests with its effects through the use of natural enemies. In other words, it is the exploitation of fungi in biological processes to lesser the insect density with the aim to reduce crop damage by insect pests. The effectiveness of myco-biocontrol agents depend on the susceptibility of the insect and also virulence of the fungus. Virulence of the fungus depends on the selection of the stable strain with specific efficacy for the target hosts. All groups of insects may be affected and over 700 species of fungi have been recorded as pathogens. Some of these fungi have restricted to a particular host ranges, viz., Aschersonia aleyrodes infects only scale insects and whiteflies, while other fungal species have a wide 
host range, with individual isolates being more specific to target pests. Entomopathogenic fungi such as Metarhizium anisopliae and Beauveria bassiana are well characterized in respect to pathogenicity against the several insects and have been used as mycobiocontrol agents of controlling major agriculture pests. Under natural conditions, fungi are the frequent and often important natural mortality factor in insect populations. Unlike other potential biocontrol agents, fungi do not have to be ingested to infect their hosts but invade directly through the cuticle and so they can be used for control of all insects including sucking insects. Thus, entomopathogenic fungi are a major component of integrated pest management techniques as biological control agents against insect pests and other arthropods in horticulture, forestry and agriculture (Inglis et al., 2000).

\section{Sources of myco-biocontrol agents}

Entomopathogenic fungi (EPF) are widely distributed with both restricted and wide host ranges which have different biocontrol potentials against arthropods insects and plant pathogenic fungi. The origin of the entomopathogenic lifestyle may have arisen several times from a common saprophytic ancestor inhabiting soil and leaf litter (Spatafora and Blackwell, 1993). Products based on Beauveria bassiana (33.9\%) (Zengzhi et al., 2001), Metarhizium anisopliae (33.9\%), Isaria fumosorosea (5.8\%), and Beauveria brongniartii $(4.1 \%)$ are the most common among the 171 products (Faria and Wraight, 2001). Host insects belonging to orders Hemiptera, Coleoptera, Lepidoptera, Thysanoptera, and Orthoptera comprise mainly the targets. The relatively easy production of asexual spores (conidia) of the hyphomycete genera of Metarhizium (Hu and St Leger, 2002), Beauveria, Verticillium, and Paecilomyces have been under focused for research as these fungi have a wide host range along with considerable genetic diversity within species. For example, Metarhizium anisopliae var. acridum (Driver et al., 2000) is only effective against acridid insects (grasshoppers and locusts).

The commercial Beauveria bassiana-based mycoinsecticides are relatively stable compared with other biological insect control agents for lepidopteran insect pests (Rana et al., 2008; Thakur et al., 2011). Past researches have shown fungi being a potential biological control agent mainly due to their high reproductive capabilities, target specific activity, short generation time, and resting stage or saprobic phase-producing capabilities that can ensure their survival for a longer time when no host is present. Primary requirement for the use of an entomopathogenic fungus as a mycobiocontrol agent is the susceptibility of the insect with more virulence fungus. The virulence of the fungus depends on selection of a strain with stable, specific efficacy for a target host. Hence, there is an immense potential for genetic improvement of fungi for mycobiocontrol. Molecular techniques for genetic engineering for filamentous fungi provide new opportunities for the study of fungi used in myco-biocontrol of insect pests. The isolation of gene encoding pathogenesis and virulence allows rigorous testing of their role in pathogenesis and should provide a rational basis for strain improvement. The studies on the fungal pathogenesis for myco-biocontrol of insect pests are still at the preliminary stages. However, the development of molecular biological technique for entomopathogenic fungi such as Beauveria bassiana and Metarhizium anisopliae which are coupled with cloning of genes encoding putative pathogenesis determinants will create more potential candidates to manage the notorious insect pests' population.

\section{Entomopathogenic fungi}

Entomopathogenic fungi are among the first organisms to be used for the biological control of pests. A group of fungi that kill an insect by attacking and infecting its insect host is called entomopathogenic fungi (Singkaravanit et al., 2010). These entomopathogens, due to their eco-friendliness and bio-persistence, are preferred to kill insects at various stages of its life cycle (Gul et al., 2014). The entomogenous word has been derived from two Greek words, "entomon" meaning insects and "genes" meaning arising in. Therefore, the etymological meaning of entomogenous microorganism is "microorganisms which arise in insects" (Sandhu et al., 2012). Entomopathogens such as Metarhizium anisopliae and Beauveria bassiana are well characterized because of their pathogenicity to several insects of different orders. Beauveria bassiana and Metarhizium anisopliae are among the first entomopathogenic fungi being successfully used for the myco-biocontrol of insect pests. In contrast to viral, bacterial and protozoan pathogens, fungi penetrate into insect directly without digestion so they are susceptible to infect on non-feeding stages of insect such as pupae. Metarhizium anisopliae and Beauveria bassiana both can infect all the life stages of insects. The details of some major entomopathogenic fungi are being elucidated in the following paragraph. 


\section{Beauveria sp.}

Beauveria bassiana, a filamentous fungus, belongs to the class Deuteromycetes also known as imperfect fungus was originally known as Tritirachium shiotae, then renamed after the Italian lawyer and scientist Agostino Bassi who first implicated it as the causative agent of a white muscardine disease in domestic silkworms (Furlong and Pell, 2005; Zimmermann, 2007). It is a fungus that grows naturally in soils and acts as a pathogen on various insect species, causing white muscardine disease (Sandhu and Vikrant, 2004; Jain et al., 2008). A broad range of Beauveria bassiana has been isolated from a variety of insect worldwide which are of agricultural importance. Hosts of agricultural and forest significance include the Colorado potato beetle, the codling moth, and several genera of termites, American bollworm, Helicoverpa armigera (Thakur et al., 2010), Hyblaeapara and Eutectona machaeralis. It can be easily isolated from insect cadavers or from soil in forested areas by using media (Beilharz et al., 1982), or by baiting soil with insects. It is being used as a biological insecticide to control many curculionidae weevils with a sub-terranean larval stage (Beavers, et al., 1983) along with termites, thrips, aphids, whiteflies and different beetles (Feng et al., 1994). It infects the insect by contact and does not need to be consumed by their host to cause infection (Dembilio et al., 2010). Like many species of entomogenous fungi, it is composed of many genetically distinct variants associated with geographical location and host which differ substantially in their ability to produce pathogenesis. As an insecticide, the spores are sprayed on affected crops as an emulsified suspension or wettable powder. It parasitizes a very wide range of arthropod hosts and therefore is considered as a nonselective biological insecticide. It is also applied against the European corn borer, Ostrinia Mubilalis., pine caterpillars, Dendrolimus spp., and green leafhoppers, Nephotettix spp.

\section{Metarhizium spp.}

Metarhizium anisopliae initially known as Entomphthora anisopliae was first described in Ukrain from infected larvae of the wheat cockchafer Anisopliae austriaca in 1879, and later on, Cleonus punctiventis by Metschnikoff. It was later renamed as Metarhizium anisopliae by Sorokin in 1883 (Tulloch, 1976). It caused a disease called "green muscardine" in insect hosts because of the development of green colour of its conidial cells. It is also very potential pathogen on insect pests and is explored for myco-biocontrol of various notorious insect pests (Sandhu et al., 1993; Sandhu and Mishra, 1994). A complete bioactivity of Metarhizium anisopliae has been tested on teak skeletonizer, Eutectona machaeralis and found that Metarhizium anisopliae to be a potential myco-biocontrol agent of teak pest (Sandhu et al., 2000). Several strains of Metarhizium anisopliae as commercial products have been developed as biological control agents for grasshoppers, locusts, cockchafers, spittlebugs, grubs, and borers and released on a large scale (Blanford et al. 2005) (Table 1).

Table 1. List of commercially available products derived from entomopathogenic fungi.

\begin{tabular}{ll}
\hline Product & Fungus \\
\hline Mycotal & \\
Verelac & Verticillium lecanii \\
Biomite & \\
Bioter & Paecilomyces fumosoroseus \\
Pfr21 & Paecilomyces lilacinus \\
Pelicide & \\
Beevicide & \\
Brocaril & \\
Ostrinil & \\
Boverol & \\
Naturalis & Beauveria bassiana \\
Mycontrol-WP & \\
Naturalis-O and & \\
BotaniGard & \\
Racer BB & \\
Bio-power & \\
Betel & \\
Engerlingspilz & \\
Melocont-Pilzgerste & Beauveria brongniartii \\
Biogreen & \\
Biopath & \\
Biologic Bio 1020 & Metarhizium anisopliae \\
Meta-Sin & \\
Trypae Mix & Homodella thompsonii \\
Mycar & \\
Nomuri &
\end{tabular}

\section{Verticillium lecanii}

It is a widely distributed fungus, which can cause large epizootic in tropical and subtropical regions, as well as in warm and humid environments. This fungus attacks nymphs and adults and stucks to the leaf underside by means of a filamentous mycelium (Nunez et al., 2008). It was reported that Verticillium lecanii was an effective biological control agent against Trialeurodes vaporariorum in South Korean greenhouses (Kim et al., 2001). In 1970s, it was developed to control whitefly and several aphids species, including the green peach aphids 
(Myzus persicae) for use in the greenhouse chrysanthemums (Hamlen et al., 1979). Toxins extracted from the mycelia of Verticillium lecanii were deleterious to Bemisia tabaci (Gennadius), Myzus persicae (Sulzer), Aphis gossypii, Acyrthosiphon pisum, (Harris) and Frankliniella occidentalis (Pergande) (Gindin et al., 1994).

\section{Nomuraea sp.}

Nomuraea rileyi poses another potential entomopathogenic fungus with a dimorphic hyphomycete that can cause epizootic death in various insects. It has been shown that many insect species belonging to Lepidoptera including Spodoptera litura and Coleoptera are susceptible to Nomuraea rileyi (Ignoff, 1981). The host specificity and its ecofriendly nature encourage its use in insect pest management. Although, its mode of infection and development have been reported for several insect hosts such as Trichoplusia ni, Heliothis zea, Plathypena scabra, Bombyx mori, Pseudoplusia includes and Anticarsia gemmatalis. Another insect Spilosoma was found to be severely attacked by Nomuraea rileyi (Mathew et al., 1998).

\section{Paecilomyces sp.}

Paecilomyces is a genus of nematophagous fungus which can kills harmful nematodes species by pathogenesis. Thus, the fungus can be used as a bio-nematicide by applying to the soil (Table 1). It also acts as one of the most important natural enemies of whiteflies worldwide, and causes the sickness called "Yellow Muscardine" (Nunez et al., 2008). Strong epizootic potential against Bemisia and Trialeurodes spp. in both greenhouse and open field environments has been reported. The ability of this fungus to grow extensively over the leaf surface under humid conditions is a characteristic that certainly enhances its ability to spread rapidly through whitefly populations (Wraight et al., 2000). It is best for controlling the nymphs of whitefly (Kim et al., 2001). These fungi cover the whiteflies body with mycelial threads and stick them to the underside of the leaves. The nymphs show a "feathery" aspect and are surrounded by mycelia and conidia (Nunez et al., 2008). P. furiosus is also used to control mosquito sp. Culex pipiens (Sandhu and Mishra., 1994).

\section{Mode of action of entomopathogenic fungi}

Entomopathogenic fungi constitute the largest single group of insect pathogens among microorganisms. Such insect killing fungi are very fast microorganisms to be recognized as disease causing agent in insects. They are promising myco-biocontrol agent for a number of crop pests of several species belonging to order Lepidoptera, Coleoptera, Homoptera, Hymenoptera, and Diptera which are susceptible to various fungal infections. Unlike other biopesticides such as bacteria and viruses, entomopathogenic fungi do not have to be ingested to cause infection, making them valuable as biological control agents. The adaptive response in entomopathogens includes formation of infective structures, extracellular enzymes (protease and lipase), production of toxins, etc. which ultimately kill the insects. Although some reports suggested that mode of infection through the siphon tips or gut of insect larvae (Lacey et al., 1988; Goettel and Inglis, 1997), entomopathogenic fungi generally infect or penetrate their targets percutaneously (Charnley, 1989). This can occur by adhesion of spores to the insect integument, especially the intersegmental folds, or by simple tarsal contact (Clarkson and Charnley, 1996).

\section{The infection process}

In contrast to bacteria and viruses that pass through the gut wall from contaminated food, fungi have a unique mode of infection. They reach the haemocoel through the cuticle or possibly through the mouth parts. Ingested fungal spores do not germinate in the gut and are voided in the faeces. The death of the insect results from a combination of factors like mechanical damage resulting from tissue invasion, depletion of nutrient resources and toxicosis as described in Fig 1 and the typical symptoms of infection on insects by various entomopathogenic fungi are depicted in Fig. 2.

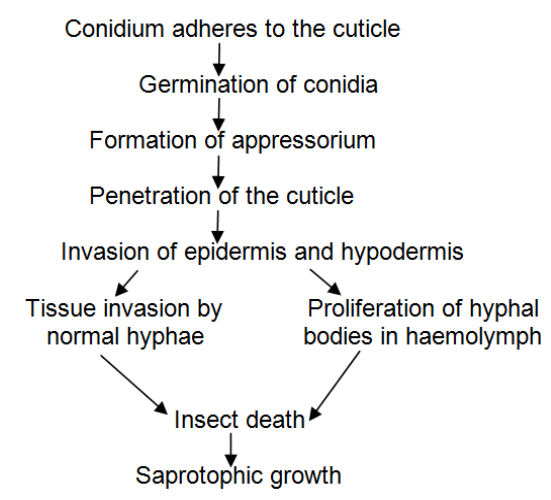

Fig. 1: Infection process of entomopathogenic fungi.

\section{Adhesion and germination of conidia}

For most of the entomopathogenic fungi host location is a random event and attachment is a passive process with the 
aid of wind or water. Attachment of a fungal spore to the cuticle surface of a susceptible host represents the initial event in the establishment of mycosis. It was observed that dry spores of Beauveria bassiana possess an outer layer composed of interwoven fascicles of hydrophobic rodlets. This rodlet layer appears to be special to the conidial stage and has not been reported on the vegetative cells. The adhesion of dry spores to the cuticle was suggested to be due to nonspecific hydrophobic forces imposed by the rodlets (Boucias et al., 1988). When the pathogen reaches and adheres to the host surface, it proceeds with rapid germination and growth which are profoundly influenced by the availability of water, nutrients, oxygen as well as $\mathrm{pH}$, temperature, and by the effects of toxic host-surface compound.

\section{Formation of an infection structure}

Entomopathogenic fungi invade their hosts by penetration of the host cuticle by making appressorium and then penetrate by penetration peg (Sandhu, 1995). The cuticle has two layers: the outer epicuticle and the procuticle. The epicuticle is a very complex thin structure that lacks chitin but contains phenol-stabilized proteins and is covered by a waxy layer containing fatty acids, lipids and sterols (Hackmann, 1984). The procuticle forms the majority of the cuticle and contains chitin fibrils embedded into a protein matrix together with lipids and quinines (Neville, 1984). In many areas of the cuticle, the chitin is organized helically giving rise to a laminate structure. Entomopathogenic fungi, Beauveria bassiana conidia germinate on the host surface and differentiate an infection structure termed appressorium. The appressorium represents an adaptation for concentrating physical and chemical energy over a very small area so that access may be achieved efficiently. Thus, formation of the appressorium plays a pivotal role in establishing a pathogenic interaction with the host. Appressorium formation may be influenced by host surface topography, and biochemical investigations indicate the involvement of the intracellular second messengers $\mathrm{Ca}^{2+}$ and cyclic AMP (cAMP) in appressorium formation (St Leger et al., 1991).

\section{Penetration of the cuticle}

Pathogenic fungi need to penetrate through the cuticle into the insect body to obtain nutrients for their growth and reproduction. Entry into the host involves both enzymic degradation and mechanical pressure as evidenced by the physical separation of lamellae by penetrated hyphae. A range of extracellular enzymes that can degrade the major components of insect cuticle, including chitinases, lipases, esterases and at least four different classes of proteases, have been suggested to function during the fungal pathogenesis. Although the complex structure of the insect cuticle suggests that penetration would require the synergistic action of several different enzymes, much of the attention has focused on the cuticle-active endoprotease as a key factor in the process. The production of cuticle-degrading enzymes by Metarhizium anisopliae during infection structure formation on Calliphora vomitoria and Manduca sexta has been investigated by biochemical and histochemical analyses both in vivo and in vitro. Among the first enzymes produced on the cuticle are endoproteases (termed PR1 and PR2) and aminopeptidases, coincident with the formation of appressoria. N-Acetylglucosaminidase is produced at a slow rate as compared to the proteolytic enzymes Chitinase and lipase activities were not detected (St Leger et al., 1989).

\section{Genetic engineering approaches for improving the efficacy of entomopathogenic fungi}

The more widespread use of fungi as myco-biocontrol agents will depend on improvements of wild-type strains by combining various characteristics of different strains and mutants. Two types of improvements could be considered: (i) improving the efficacy of the insecticide, by reducing the dose necessary to kill the insects, by reducing the time to kill the pest or decreasing crop damage caused by the pest by reducing the feeding time; (ii) expanding the host range. Essential for the development of a hypervirulent strain is a complete understanding of the remarkable pathology of fungal infections. Molecular biology provides the necessary tools for dissecting the mechanisms of pathogenesis and in the longer term for producing recombinant organisms with new and relevant characteristics. Initial development towards these goals has occurred with Metarhizium anisopliae and to a much lesser extent with Beauveria bassiana (Hegedus et al., 1991). Genetic transformation systems have been established for the experimental manipulation of virulence genes in vitro and in vivo (Hasan et al., 2002; Sandhu and Vikrant, 2006). The success of utilizing these procedures depends on the availability of selectable transformation markers (Sandhu et al., 2000). Transformation techniques have been used to isolate specific pathogenic genes, investigate virulence determinants of Metarhizium anisopliae and Beauveria bassiana, and to produce a strain with enhanced virulence. Unraveling the molecular mechanisms of fungal pathogenesis in insects will provide the basis for the genetic engineering of entomopathogenic fungi. 


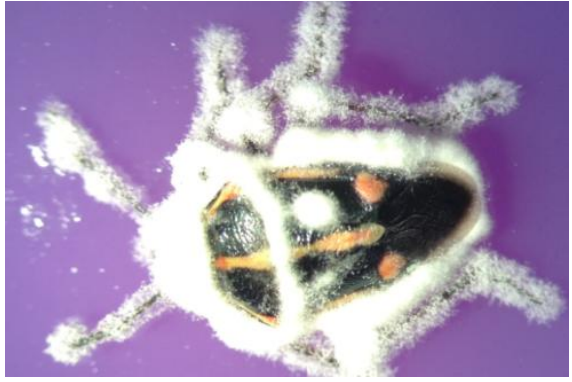

(a)

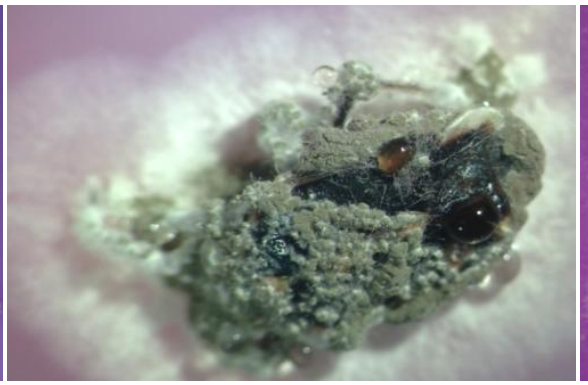

(b)

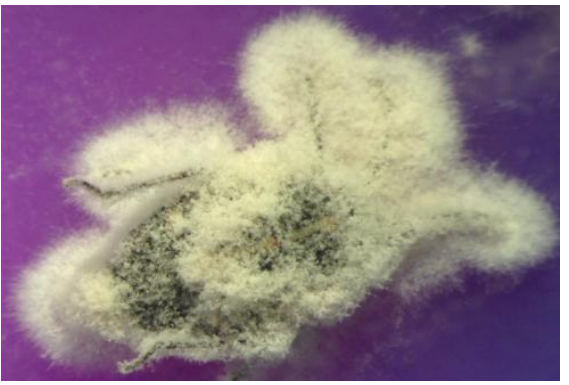

(c)

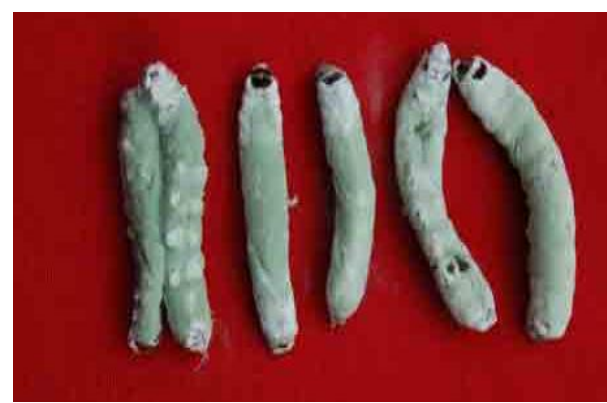

(d)

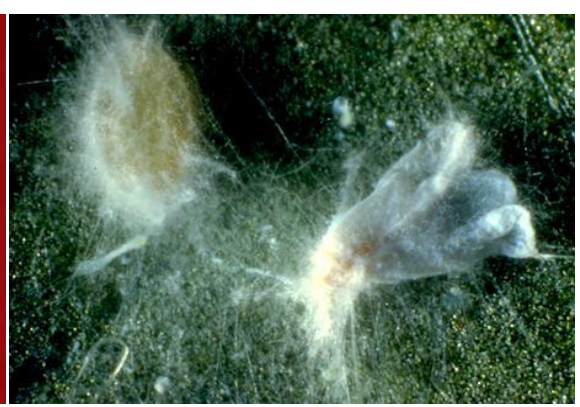

(e)

Fig 2: Typical symptoms of infection on insects by various entomopathogenic fungi, a) Bagrada bug killed by the white fungus, Beauveria bassainia, b) Bagrada bug killed by the green fungus, Metarhizium anisopliae, c) Bagrada bug killed by Paecilomyces fumosoroseus, d) Spodoptera larvae infected with Nomuraea sp., e) Verticillium leucani infecting on whitefly.

\section{Elucidation on molecular studies of entomopathogenic fungi}

A number of unspecific DNA based methods have been used specially in Beauveria (Glare et al., 2008). Random amplified polymorphic DNA (RAPD) has been used in many studies. It is based on the use of short general primers that anneal to unspecified regions in the template DNA whereas universally primed (UP) PCR is based on longer general primers and a higher annealing temperature which makes it more robust in terms of reproducibility (Bulat et al., 1998; Bulat et al., 2000; Lubeck et al., 1999; Sabu et al., 2011). UP-PCR has been used to separate sympatric isolates of Beauveria in Denmark and was used to place isolates in genetic groups (Meyling and Eilenberg, 2006).

For ecological studies, random amplified polymorphic DNA (RAPD) was used in combination with specific methods to separate isolate genotypes of Metarhizium anisopliae from Canadian soil (Bidochka et al., 2001) and to relate these genotypes to the origin of isolation. Beauveria bassiana and Metarhizium anisopliae (Aquino de Muro et al., 2003; Aquino de Muro et al., 2005; Inglis et al., 2008), have been characterized using AFLP (amplified fragment length polymorphism), inter-simplesequence repeats (ISSR), simple sequence repeats (SSRs), or microsatellites. Internal transcribed spacer sequences (ITSs) have been widely used in fungal systematics (Driver et al., 2000; Bowman et al., 1992). In case of the genus Paecilomyces, analysis of sequences of the large and small subunit rRNA gene has already indicated the polyphyly of the genus (Obornik et al., 2001; Inglis and Tigano, 2006). Recent development of microsatellite markers (Rehner and Buckley, 2003; Enkerli et al., 2005), has surely provided an insight in the population ecology of Beauveria bassiana and Metarhizium anisopliae. Expressed sequence tag (EST) analysis of entomopathogenic fungus Beauveria bassiana has been studied using cDNA libraries (Cho et al., 2006) and EST analysis of two subspecies of Metarhizium anisopliae revealed a distinct patterns of expression of proteases and pathogenicity factors that led to the ability to examine gene expression during infection of various insect hosts (Freimoser et al., 2003).

\section{Advantages of application of entomopathogenic fungi as myco-biocontrol agents}

The advantages of using fungi as myco-biocontrol agents are as follows:

(1) Their high degree of specificity for pest control enables to control harmful insect pests without affecting beneficial insect predators and nonharmful parasites. 
(2) Their absence of effects on mammals lead in reduction of pollution of the environmental hazards normally encountered with insecticide applications.

(3) The less chance of developing resistance to insect and prolonged pest control.

(4) A high potential for further development by biotechnological research.

(5) High persistence in the environment provides long-term effects on pest suppression.

\section{Disadvantages of application of entomopathogenic fungi as myco-biocontrol agents}

A number of constraints on the use of fungi as mycobiocontrol agents are given below:

(1) Long time taking to kill the insects (2-3 weeks) as compared to chemical insecticides.

(2) Application needs to coincide with high relative humidity, low pest numbers and a fungicide free period.

(3) Due to the high specificity additional control agents are needed as integrated approach for other pests.

(4) Their production is relatively expensive and the short shelf life of spores.

(5) Insect-specific application techniques need to be optimized to retain long-term impacts.

(6) A potential risk to immunodepressive people.

\section{Conclusion}

The utilization of entomopathogenic fungi in biological control of many insect pests is rising greatly due to their greater environmental awareness, food safety concerns and the less chance of developing resistance as compared to conventional chemicals. Entomopathogenic fungi being component of an integrated approach can provide significant and selective insect control towards all fields of agriculture, sustainable agriculture, forestry and horticulture. Several modern techniques of genetic engineering could extremely helpful in manipulating the desired traits in improving the efficacy of entomopathogenic fungi for more successful result of overall field activity. Thus, the future efforts in genetic engineering could be focused on producing targetspecific which will alleviate any environmental safety concerns and also allow designing multiple pathogens with different strategies to be used for different ecosystems and avoid the possibility of the host developing resistance.

\section{Conflict of interest statement}

Authors declare that they have no conflict of interest.

\section{References}

Aquino de Muro, M., Elliott, S., Moore, D., Parker, B.L., Skinner, M., Reid, W., El Bouhssini, M., 2005. Molecular characterisation of Beauveria bassiana isolates obtained from overwintering sites of Sunn Pests (Eurygaster and Aelia species). Mycol. Res. 109(3), 294-306.

Aquino de Muro, M., Mehta, S., Moore, D., 2003. The use of amplified fragment length polymorphism for molecular analysis of Beauveria bassiana isolates from Kenya and other countries and their correlation with host and geographical origin. FEMS Microbiol. Lett. 229, 249-257.

Beavers, J.B., McCoy, C.W., Kaplan, D.T., 1983. Natural enemies of sub-terranean Diaprepes abbbreviatus (Coleoptera: Curculionidae) larvae in Florida. Environ. Entomol. 12(3), 840-843.

Beilharz, V.C., Parberry, D.G., Swart, H.J., 1982. Dodine: A selective agent for certain soil fungi. Trans. British Mycol. Soc. 79(3), 507-511.

Bidochka, M.J., Kamp, A.M., Lavender, T.M., Dekoning, J., De Croos, J.N.A., 2001. Habitat association in two genetic groups of the insect-pathogenic fungus Metarhizium anisopliae: uncovering cryptic species? Appl. Environ. Microbiol. 67(3), 1335-1342.

Blanford, S., Chan, B.H., Jenkins, N., Sim, D., Turner, R.J., Read, A.F., Thomas, M.B. 2005. Fungal pathogen reduces potential for malaria transmission. Science. 308, 16381641.

Boucias, D.G., Pendland, J.C., Latge, J.P., 1988. Nonspecific factors involved in the attachment of entomopathogenic Deuteromycetes to host insect cuticle. Appl. Environ. Microbiol. 54(7), 1795-1805.

Bowman, B.H., Taylor, J.W., Brownlee, A.G., Lee, J., Lu, S.D., White, T.J., 1992. Molecular evolution of the fungi: relationship of the Basidiomycetes, Ascomycetes, and Chytridiomycetes. Mol. Biol. Evol. 9(2), 285-296.

Bulat, S.A., Lubeck, M., Alekhina, I.A., Jensen, D.F., Knudsen, I.M.B., Lubeck, P.S., 2000. Identification of a universally primed-PCR-derived sequence-characterized amplified region marker for an antagonistic strain of Clonostachys rosea and development of a strain-specific PCR detection assay. Appl. Environ. Microbiol. 66(11), 4758-4763.

Bulat, S.A., Lubeck, M., Mironenko, N., Jensen, D.F., Lubeck, P.S., 1998. UP-PCR analysis and ITS1 ribotyping of strains of Trichoderma and Gliocladium. Mycol. Res. 102(8), 933-943.

Charnley, A.K., 1989. Mechanisms of fungal pathogenesis in insects. In: The Biotechnology of fungi for improving plant growth (Eds.: Whipps, J.M., Lumsden, R.D.), Cambridge University, London. pp.85-125.

Cho, E.M., Liu, L., Farmerie, W., Keyhani, N.O., 2006. EST analysis of cDNA libraries from the entomopathogenic 
fungus Beauveria (Cordyceps) bassiana. I. Evidence for stage-specific gene expression in aerial conidia, in vitro blastospores and submerged conidia. Microbiology. 152(9), 2843-2854.

Clarkson, J.M., Charnley, A.K., 1996. New insights into the mechanisms of fungal pathogenesis in insects. Trend. Microbiol. 4(5), 197-203.

Dhaliwal, G. S., Koul, O., 2007. Biopesticide and Pest Management: Conventional and Biotechnological Approaches, Kalyani Publishers, New Delhi. 455p.

Dembilio, O., Quesada-Moraga, E., Santiago-Álvarez, C., Jacas, J.A., 2010. Potential of an indigenous strain of the entomopathogenic fungus Beauveria bassiana as a biological control agent against the Red Palm Weevil, Rhynchophorus ferrugineus. J. Invertebr. Pathol. 104(3), 214-221.

Driver, F., Milner, R.J., Trueman, J.W.H., 2000. A taxonomic revision of Metarhizium based on a phylogenetic analysis of rDNA sequence data. Mycol. Res. 104(2), 134-150.

Enkerli, J., Kolliker, R., Keller, S., Widmer, F., 2005. Isolation and characterization of microsatellite markers from the entomopathogenic fungus Metarhizium anisopliae. Mol. Ecol. Notes. 5(2), 384-386.

Faria, M., Wraight, S.P., 2001. Biological control of Bemisia tabaci with fungi. Crop Prot. 20(9), 767-778.

Feng, M.G., Poprawski, T.J., Khachatourians, G.G., 1994. Production, formulation and application of the entomopathogenic fungus Beauveria bassiana for insect control: current status. Biocontrol Sci. Technol. 4(1), 334.

Freimoser, F.M., Screen, S., Bagga, S., Hu, G., St Leger, R.J., 2003. Expressed sequence tag (EST) analysis of two subspecies of Metarhizium anisopliae reveals a plethora of secreted proteins with potential activity in insect hosts. Microbiology. 149(1), 239-247.

Furlong, M.J., Pell, K.J., 2005. Interactions between entomopathogenic fungi and arthropod natural enemies, In: Insect-fungal Associations: Ecology and Evolution (Eds.: Vega, F.E., Blackwell, M.), Oxford University Press. pp.51-73.

Gindin, G., Barash, I., Harari, N. and Raccah, B. 1994. Effect of endotoxic compounds isolated from Verticillium lecanii on the sweet potato whitefly, Bemisia tabaci. Phytoparasitica 22, 189-196.

Glare, T.R., Reay, S.D., Nelson, T.L., Moore, R., 2008. Beauveria caledonica is a naturally occurring pathogen of forest beetles. Mycol. Res. 112(3), 352-360.

Goettel, M.S., Inglis, G.D., 1997. Fungi: Hyphomycetes, In: Manual of Techniques in Insect Pathology (Ed.: Lacey, L.A.). Academic Press, London. pp. 213-250.

Gul, H.T., Saeed, S., Khan, F.Z.A. 2014. Entomopathogenic Fungi as Effective Insect Pest Management Tactic: A Review. Appl. Sci. Business Econom. 1(1) 10-18.

Hackman, R.H., 1984. Cuticle: biochemistry. In: Biology of the Integument (Eds.: Bereiter-Hahn, J., Matolts, A.G., Richards, K.S.). Springer, Berlin, Germany. pp.626-637.

Hamlen, R.A., 1979. Biological control of insects and mites on
European greenhouse crops: research and commercial implementation. Proc. Florida State Hortic. Soc. 92, 367368.

Hasan, S., Bhamra, A.K., Sil, K., Rajak, R.C., Sandhu, S.S., 2002. Spore production of Metarhizium anisopliae By Solid State fermentation. J. Ind. Bot. Soc. 8, 85-88.

Hegedus, D.D., Pfeifer, T.A., MacPherson, J.M., Khachatourians, G.G., 1991. Cloning and analysis of five mitochondrial tRNA-encoding genes from the fungus Beauveria bassiana. Gene. 109(1), 149-154.

$\mathrm{Hu}, \mathrm{G} .$, St Leger, R.J., 2002. Field studies using a recombinant mycoinsecticide (Metarhizium anisopliae) reveal that it is rhizosphere competent. Appl. Environ. Microbiol. 68(12), 6383-6387.

Ignoffo, C.M., 1981. The fungus Nomuraea rileyi as a microbial insecticide. In: Microbial Control of Pests and Plant Diseases (Ed.: Burges, H.D.). Academic Press, London, UK. pp.513-538.

Inglis, G.D., Ivie, T.J., Duke, G.M., Goettel, M.S., 2000. Influence of rain and conidial formulation on persistence of Beauveria bassiana on potato leaves and Colorado potato beetle larvae. Biol. Cont. 18(1), 55-64.

Inglis, G.D., Duke, G.M., Goettel, M.S., Kabaluk, J.T., 2008. Genetic diversity of Metarhizium anisopliae var. anisopliae in southwestern British Columbia. J. Invertebr. Pathol. 98(1), 101-113.

Inglis, P.W., Tigano, M.S., 2006. Identification and taxonomy of some entomopathogenic Paecilomyces spp. (Ascomycota) isolates using rDNA-ITS sequences. Genet. Mol. Biol. 29(1), 132-136.

Jain, N., Rana, I.S., Kanojiya, A., Sandhu, S.S., 2008. Characterization of Beauveria bassiana strains based on protease and lipase activity and their role in pathogenicity. J. Basic Appl. Mycol. I-II, 18-22.

Kim, J.J., Lee, M.H., Yoon, C.S., Kim, H.S., Yoo, J.K., Kim, 93 K.C., 2001. Control of cotton aphid and greenhouse whitefly with a fungal pathogen. In: Biological control of greenhouse pests. Food \& Fertilizer Technology Center Extension Bulletin 502, Food \& Fertilizer Technology Center, Taipei, Taiwan. pp.7-14.

Lacey, C.M., Lacey, L.A., Roberts, D.R., 1988. Route of invasion and histopathology of Metarhizium anisopliae in Culex quinquefasciatus. J. Invertebr. Pathol. 52(1), 108118.

Lubeck, M., Alekhina, I.A., Lubeck, P.S., Jensen, D.F., Bulat, S.A., 1999. Delineation of Trichoderma harzianum into two different genotypic groups by a highly robust fingerprinting method, UP-PCR, and UP-PCR product cross-hybridization. Mycol. Res. 103(3), 289-298.

Mathew, S.O., Sandhu, S.S., Rajak, R.C., 1998. Bioactivity of Nomuraea rileyi against Spilosoma obliqua: effect of dosage, temperature and relative humidity. J. Ind. Bot. Soc. 77, 23-25.

Meyling, N.V., Eilenberg, J., 2006. Isolation and characterization of Beauveria bassiana isolates from phylloplanes of hedgerow vegetation. Mycol. Res. 110(2), 188-195. 
Neville, A.C., 1984. Cuticle: organization. In: Biology of the Integument (Eds.: Bereiter-Hahn, J., Matolts, A.G., Richards, K.S.). Springer, Berlin, Germany. pp.611-625.

Nunez, E., Iannacone, J., Gomez, H., 2008. Effect of two entomopathogenic fungi in controlling Aleurodicus cocois (Curtis, 1846) (Hemiptera: Aleyrodidae). Chil. J. Agric. Res. 68(1), 21-30.

Obornik, M., Jirku, M., Dolezel, D., 2001. Phylogeny of mitosporic entomopathogenic fungi: is the genus Paecilomyces polyphyletic? Canad. J. Microbiol. 47(9), 813-819.

Rana, I.S., Kanojiya, A., Sandhu, S.S. 2008. Mosquito larvicidal potential of fungi isolated from larval mosquito habitats against Aedes aegypti. J. Biol. Control. 22, 179183.

Rehner, S.A., Buckley, E.P., 2003. Isolation and characterization of microsatellite loci from the entomopathogenic fungus Beauveria bassiana (Ascomycota: Hypocreales). Mol. Ecol. Notes. 3(3), 409-411.

Sabu, T.K., Shiju, R.T., Vinod, K.V., Nithya, S., 2011. A comparison of the pitfall trap, Winkler extractor and Berlese funnel for sampling ground-dwelling arthropods in tropical montane cloud forests. J. Insect Sci. 11(28), 1-19.

Sandhu, S.S., 1995. Effect of physical factors on germination of entomopathogenic fungus Beauveria bassiana conidia. Nat. Acad. Sci. Lett. 18, 1-5.

Sandhu, S.S., Mishra, M., 1994. Larvicidal activity of fungal isolates Beauveria bassiana, Metarhizium anisopliae and Aspergillus flavus against mosquito sp. Culex pipiens. Proceedings of the National Symposium on Advances in Biological Control of Insect Pests, Muzaffarnagar, India. pp.145-150.

Sandhu, S.S., Rajak, R.C., Agarwal, G.P., 1993. Studies on prolonged storage of Beauveria bassiana conidia: effects of temperature and relative humidity on conidial viability and virulence against chickpea borer, Helicoverpa armigera. Biocontrol Sci. Technol. 3, 47-53.

Sandhu, S.S., Rajak, R.C., Hasija, S.K., 2000. Potential of entomopathogens for the Biological management of medically important pest: progress and prospect. In: Glimpses in Plant Sciences. pp.110-117.

Sandhu, S.S., Vikrant, P., 2004. Myco-insecticides: control of insect pests, In: Microbial Diversity: Opportunities \& Challenges (Eds.: Gautam, S.P., Sandhu, S.S., Sharma, A., Pandey, A.K.). Indica Publishers, New Delhi, India.

Sandhu, S.S., Vikrant, P., 2006. Evaluation of mosquito larvicidal toxins in the extra cellular metabolites of two fungal genera Beauveria and Trichoderma. In: Emerging Trends in Mycology, Plant Pathology and Microbial Biotechnology (Eds.: Bagyanarayana, G., Bhadraiah, B., Kunwar, I.K.), BS, Hyderabad, India.

Sandhu, S.S., Sharma, A. K., Beniwal, V., Goel, G., Batra, P., Kumar, A., Jaglan, S., Sharma, A. K., Malhotra, S., 2012. Myco-biocontrol of insect pests: Factors involved, mechanism, and regulation. J. Pathogens. 1, 1-10.

Singkaravanit, S., Kinoshita, H., Ihara, F., Nihira, T., 2010. Cloning and functional analysis of the second geranylgeranyl diphosphate synthase gene influencing helvolic acid biosynthesis in Metarhizium anisopliae. Appl. Microbiol. Biotechnol. 87(3), 1077-1088.

Spatafora,J.W., Blackwell, M., 1993. Molecular systematic of unitunicate perithecia ascomycetes: the ClavicipitalesHypocreales connection. Mycologia. 85, 912-922.

St Leger, R.J., Butt, T.M., Staples, R.C., Roberts, D.W., 1989. Synthesis of proteins including a cuticle-degrading protease during differentiation of the entomopathogenic fungus Metarhizium anisopliae. Exp. Mycol. 13(3), 253262.

St Leger, R.J., Roberts, D.W., Staples, R.C., 1991. A model to explain differentiation of appressoria by germlings of Metarhizium anisopliae. J. Invertebr. Pathol. 57(3), 299310.

Thakur, R., Jain, N., Pathak, R., Sandhu, S.S., 2011. Practices in wound healing studies of plants. Evidence-Based Compl. Alt. Med. 2011, Article ID 438056.

Thakur, R., Sandhu, S.S., 2010. Distribution, occurrence and natural invertebrate hosts of indigenous entomopathogenic fungi of Central India. Ind. J. Microbiol. 50(1), 89-96.

Tulloch, M., 1976. The genus Metarhizium. Trans. British Mycol. Soc. 66, 407-411.

Wraight, S.P., Carruthers, R.I., Jaronski, S.T., Bradley, C.A., Garza, C.J., Wraight, S.G., 2000. Evaluation of the entomopathogenic fungi Beauveria bassiana and Paecilomyces fumosoroseus for microbial control of the silver leaf whitefly, Bemisia argentifolii. Biol. Control. 17, 203-217.

Zengzhi, Li., Chunru, Li., Bo, H., Meizhen, F., 2001. Discovery and demonstration of the teleomorph of Beauveria bassiana (Bals.) Vuill., an important entomogenous fungus. Chinese Sci. Bull. 46(9), 751-753.

Zimmermann, G., 2007. Review on safety of the entomopathogenic fungus Beauveria bassiana and Beauveria brongniartii. Biocontrol Sci. Technol. 17(5/6), 553-596.

\section{How to cite this article:}

Bidyarani Devi, E., Premabati Devi, E., Deepshikha., 2016. A review on prospects of entomopathogenic fungi as a potent biological control of insect pests. Int. J. Curr. Res. Biosci. Plant Biol. 3(9), 74-82. doi: http://dx.doi.org/10.20546/ijcrbp.2016.309.011 